\title{
Transtentorial dissemination of optic nerve glioblastoma: case report
}

\author{
Panagiotis Mastorakos, MD, ${ }^{1}$ Michael A. Hays, MD, ${ }^{2}$ James P. Caruso, BS, ${ }^{1}$ Ching-Jen Chen, MD, ${ }^{1}$ \\ Dale Ding, MD, ${ }^{1}$ Davis G. Taylor, MD, ${ }^{1}$ M. Beatriz Lopes, MD, PhD, ${ }^{1,2}$ and Mark E. Shaffrey, MD1 \\ 1Department of Neurological Surgery and 2Division of Neuropathology, University of Virginia Health System,
Charlottesville, Virginia
}

\begin{abstract}
Optic nerve glioblastoma is a rare entity that usually presents with rapidly progressive vision loss, which eventually results in blindness and, ultimately, death. As with malignant gliomas in other anatomical locations, local recurrence is common. Isolated rapid changes in vision, atypical neuroimaging findings, and the rarity of optic nerve glioblastoma may render diagnosis challenging and, thus, delay treatment. The authors present a case of optic nerve glioblastoma that was treated with subtotal resection followed by adjuvant radiation therapy and temozolomide. One year following the initial diagnosis, the patient developed a right cerebellar lesion, which was histopathologically consistent with glioblastoma. This case represents the first report of transtentorial dissemination of an optic nerve glioblastoma. In addition, the authors reviewed the literature regarding optic nerve glioblastomas. Of the 73 previously reported cases of malignant optic nerve gliomas, 32 were histologically confirmed glioblastomas. The mean age at diagnosis was 62 years, and $56 \%$ were male; the median survival was 7 months. A malignant glioma of the optic nerve should be considered in the differential diagnosis of a patient with rapidly progressive visual loss. However, the incidence of optic nerve glioblastoma is exceedingly low.
\end{abstract}

https://thejns.org/doi/abs/10.3171/2016.10.JNS161443

KEY WORDS glioblastoma; optic nerve; case report; review; oncology

\section{$\mathrm{M}$} ALIGNANT gliomas are the most common and aggressive primary brain tumors. They are most often located in the supratentorial compartment. ${ }^{29}$ Malignant optic nerve glioma (MONG) constitutes a rare entity that typically arises in the optic nerve or chiasm but may also present as a part of a multifocal disease process. ${ }^{37}$ Patients with MONGs most commonly present with rapidly progressive vision loss, which eventually results in blindness. Similar to malignant gliomas in other locations, these lesions confer a dismal prognosis, with an associated overall survival of less than 2 years. ${ }^{35,37}$ These tumors are frequently misdiagnosed as inflammatory or nongliomatous neoplastic processes on initial presentation; thus, a biopsy is often required to confirm the diagnosis. ${ }^{24,28}$

While malignant gliomas are considered a diffusely disseminated disease, tumor recurrence most frequently occurs locally, with reported rates ranging from $70 \%$ to $100 \% .{ }^{8,20}$ As reported by Sherriff et al., the majority of supratentorial glioblastomas with recurrence were observed in the ipsilateral hemisphere, and only $4 \%$ of the total re- currences were found in the contralateral hemisphere. ${ }^{33}$ Transtentorial dissemination of malignant glioma is extremely rare, with only 2 case reports in the literature. . $^{16,36}$ To our knowledge, we present the first case of transtentorial spread of an optic nerve glioblastoma to the cerebellum.

\section{Case Report History and Examination}

A 66-year-old man presented to the ophthalmology clinic with progressively worsening right monocular nasal hemifield visual deficit and reduced visual acuity in his right eye persisting for approximately 1 year, with subsequent development of visual deficits in his left eye. On ophthalmological examination, the patient's visual acuity was $3 / 200$ and $2 / 30$ in his right and left eyes, respectively, with absent color vision in the right eye and a right afferent pupillary defect. He had a dense nasal defect in the right eye, as well as a relative temporal defect in the left eye, as confirmed by single-field analysis (Fig. 1A). 

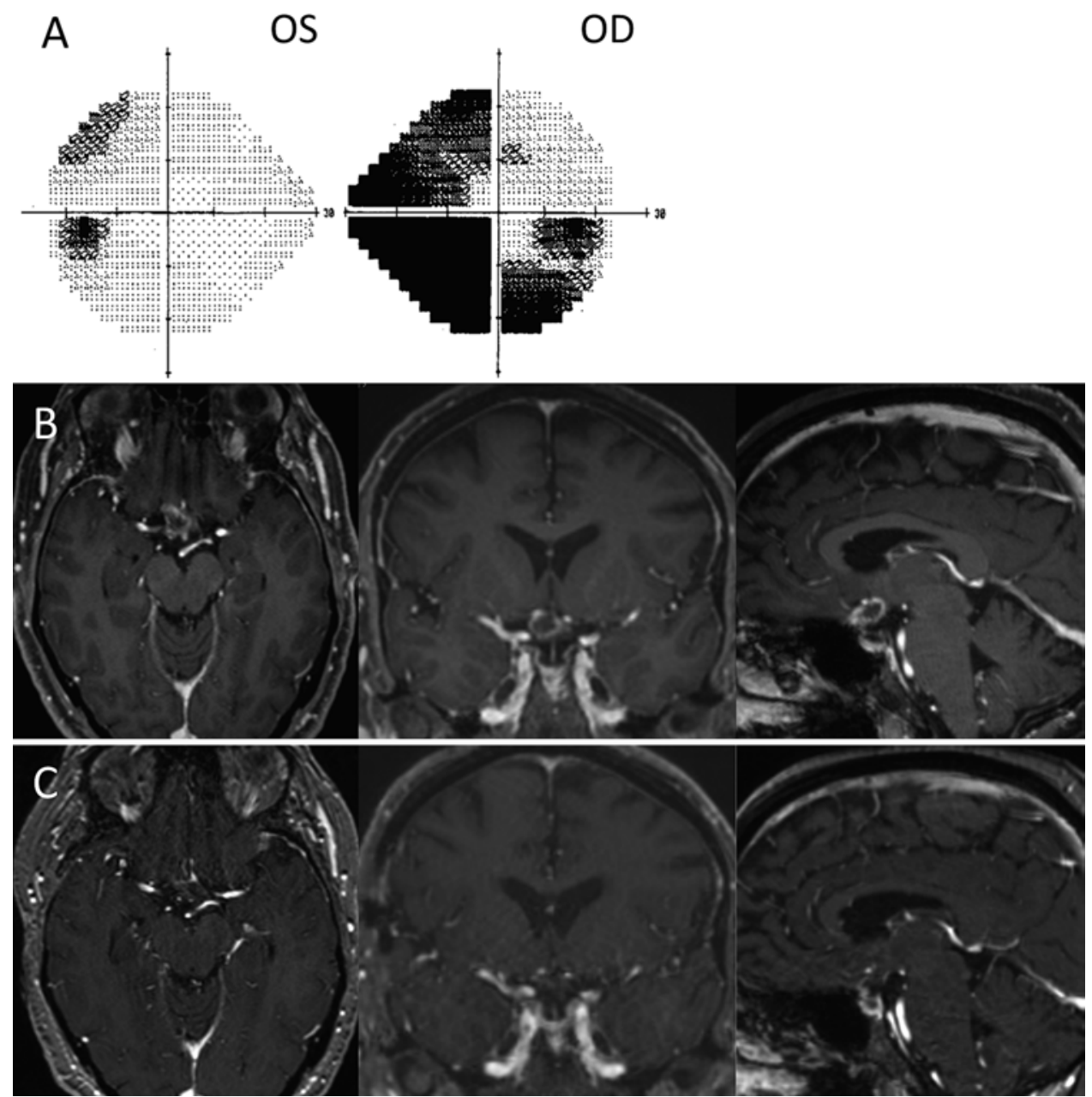

FIG. 1. A: Single-field analysis at presentation. OD = right eye; OS = left eye. B: Preoperative postcontrast T1-weighted MR images (axial, coronal, and sagittal) demonstrating a peripherally enhancing lesion centered on the right side of the optic chiasm, extending into both the pre- and postchiasmatic right optic nerves. The mass abuts the right side of the pituitary infundibulum, the underside of the $A_{1}$ segment of the right anterior cerebral artery, and the right carotid terminus. No other intracranial enhancing masses are present. C: Postoperative postcontrast T1-weighted MR images (axial, coronal, and sagittal) obtained 10 months following resection, remaining stable and demonstrating small residual contrast enhancement at the base of the right optic nerve that was not changed from prior examination.

MRI revealed a peripherally enhancing lesion centered on the right side of the optic chiasm, extending into both the prechiasmatic right optic nerve and postchiasmatic right optic tract. The mass was adjacent to the right side of the infundibulum, the underside of the $A_{1}$ segment of the anterior cerebral artery, and the right internal carotid artery terminus. The lesion was initially thought to be a meningioma, and no other intracranial enhancing lesions were present (Fig. 1B).

\section{First Operation and Postoperative Course}

The patient underwent a right pterional craniotomy for biopsy sampling and debulking of the optic chiasm lesion under the guidance of frameless stereotactic neuronavigation and intraoperative MRI. Postoperative MRI demonstrated a small amount of residual contrast enhancement at the base of the right optic nerve, which remained stable on repeat imaging at up to 12 months of follow-up (Fig. 1C). The optic nerve lesion was determined to be a glioblas- toma based on histopathological analysis. Postoperatively, the patient was treated with a course of fractionated radiation therapy (60 Gy) with concomitant temozolomide. On ophthalmological follow-up, the patient developed gradual worsening of his left homonymous hemianopia and worsening of mean sensitivity in his left eye but slightly improved right-eye acuity. Of note, preoperative images demonstrated no evidence of contrast enhancement or hyperintensity to indicate dissemination of glioblastoma to the cerebellum. However, follow-up imaging performed at 12 months demonstrated small foci of hyperintensity on T2-weighted imaging, suggestive of possible initiation of tumor infiltration to the cerebellum (Fig. 2).

\section{Second Operation and Postoperative Course}

Approximately 14 months after the initial diagnosis and following completion of 10 cycles of temozolomide, routine follow-up imaging showed a new homogeneously enhancing mass, measuring $2.7 \times 2.4 \times 2.2 \mathrm{~cm}$, with sur- 

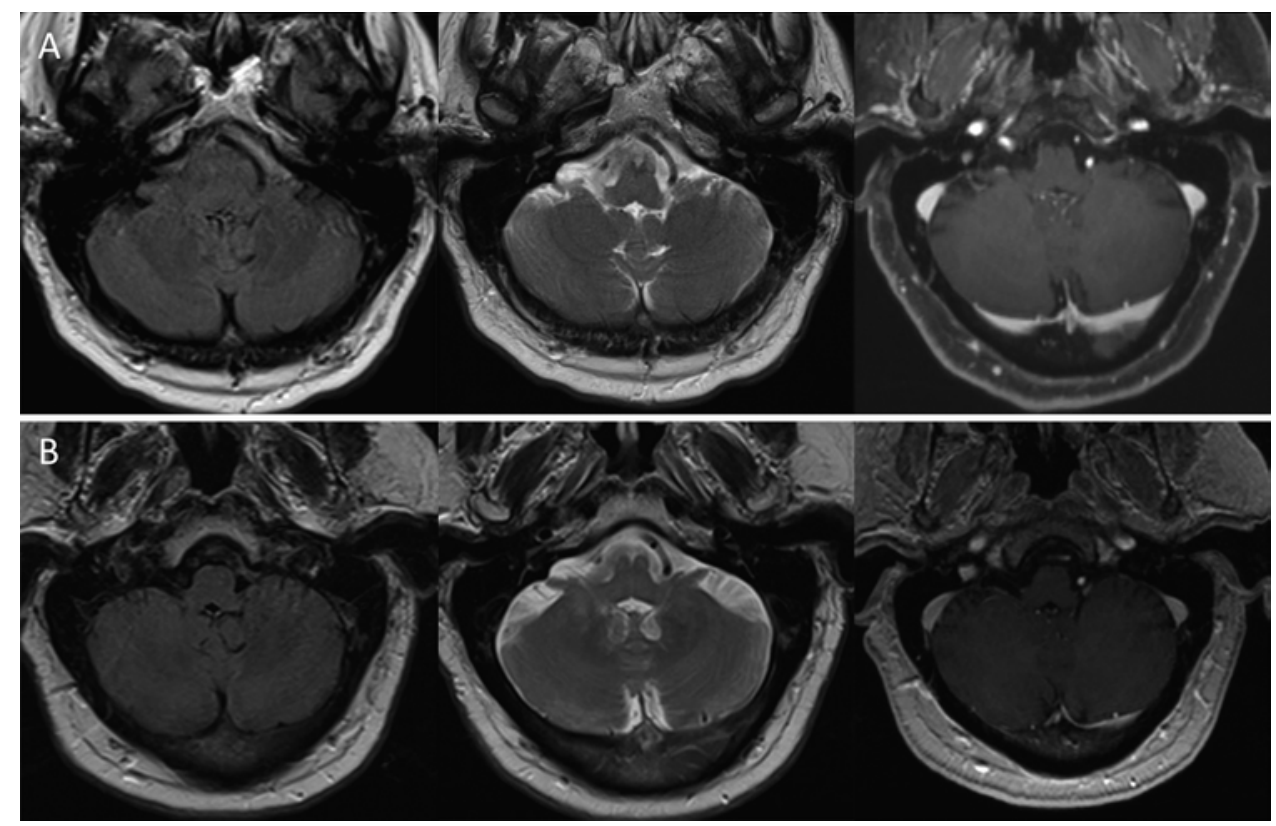

FIG. 2. FLAIR (left), T2 weighted (center), and T1-weighted postcontrast (right) preoperative images (A) and postoperative images obtained 12 months after MONG resection (B). The preoperative images demonstrate no evidence of contrast enhancement or hyperintensity to indicate dissemination of glioblastoma to the cerebellum at this time point. Follow-up images obtained at 12 months demonstrated small foci of hyperintensity on the T2-weighted image, suggestive of possible initiation of tumor infiltration to the cerebellum.

rounding satellite enhancing lesions in the right inferior cerebellar hemisphere, extending into the right cerebellar tonsil (Fig. 3A and B). There was no evidence of a direct connection between the previously resected MONG and the newly diagnosed lesion (Fig. 3C). The patient underwent a suboccipital craniectomy for resection of the right cerebellar lesion, and intraoperative MRI did not demonstrate any abnormal residual contrast enhancement (Fig. 3D and E). The histopathological results of the cerebellar lesion were consistent with a glioblastoma. Follow-up imaging at 1 month demonstrated local recurrence (Fig. $3 \mathrm{~F})$. The patient was then treated with another course of fractionated radiation therapy (25 Gy) with concomitant temozolomide. The cerebellar tumor progressed, and the patient died 2 months after the second surgery and a total of 16 months from initial diagnosis.

\section{Histopathological Examination}

Histopathological analysis of the right optic nerve tumor demonstrated findings consistent with glioblastoma (WHO Grade IV) (Fig. 4). Immunostaining for mutant IDH-1 (R132H) was diffusely negative, and p53 immunostain was weakly positive. A pyrosequencing assay demonstrated MGMT promoter hypermethylation. The histopathology of the right cerebellar lesion was also consistent with a glioblastoma (Fig. 5). Similar to the optic lesion, there was no evidence of IDH-1 (R132H) mutation on immunohistochemical analysis, and p53 immunostaining showed minimal positivity.

\section{Discussion}

MONG was first described by Hoyt et al. in $1973 .^{17}$ Since then, there have been 73 reported cases of MONGs in the literature. ${ }^{35,37}$ Among these, 32 were confirmed to be glioblastomas, with a mean patient age of 62 years at the time of diagnosis. $2,4,7,10-13,25,27,28,30,34,35,37,39$ Fourteen of the patients were female (44\%) and 18 were male $(56 \%)$. The median overall survival of the reported cases of optic nerve glioblastoma was 7 months (Table 1).

As seen in our case, patients with optic nerve glioblastomas usually present with a progressive decline in visual acuity and visual field deficits, eventually resulting in blindness. While the majority of patients initially present with monocular symptoms, nearly all patients eventually develop bilateral visual deficits due to infiltration of the optic chiasm and contralateral optic nerve. ${ }^{26,37}$ Additionally, symptoms, such as headaches, behavioral changes, and motor deficits, have been reported..$^{5,14,23}$

Optic nerve glioblastomas most commonly present as primary lesions involving the anterior portion of the optic tract and optic chiasm. Among the reported optic nerve glioblastoma cases, 5 presented with extensive involvement of contiguous structures $(16 \%),{ }^{14,15,23,35}$ and 5 were a part of multifocal glioblastoma. ${ }^{1,24,35}$

The diagnosis of optic nerve glioblastoma can be challenging, ${ }^{28}$ since initial neuroimaging may demonstrate an edematous, thickened optic nerve; ;,19,21 anterior optic tract contrast enhancement; $;, 28$ an enhancing space-occupying cystic $^{5}$ or solid lesion; $;, 7$ or multifocal enhancing lesions with optic nerve involvement. ${ }^{1,24}$ Considering that optic nerve glioblastoma is a rare entity, the differential diagnosis in patients suspected of harboring these lesions should remain broad. However, one must keep in mind that the variety of neoplastic, infectious, and inflammatory conditions, such as optic neuritis, ${ }^{35}$ nonarteritic ${ }^{4}$ or arteritic ${ }^{24}$ anterior ischemic optic neuropathy, central retinal artery or 

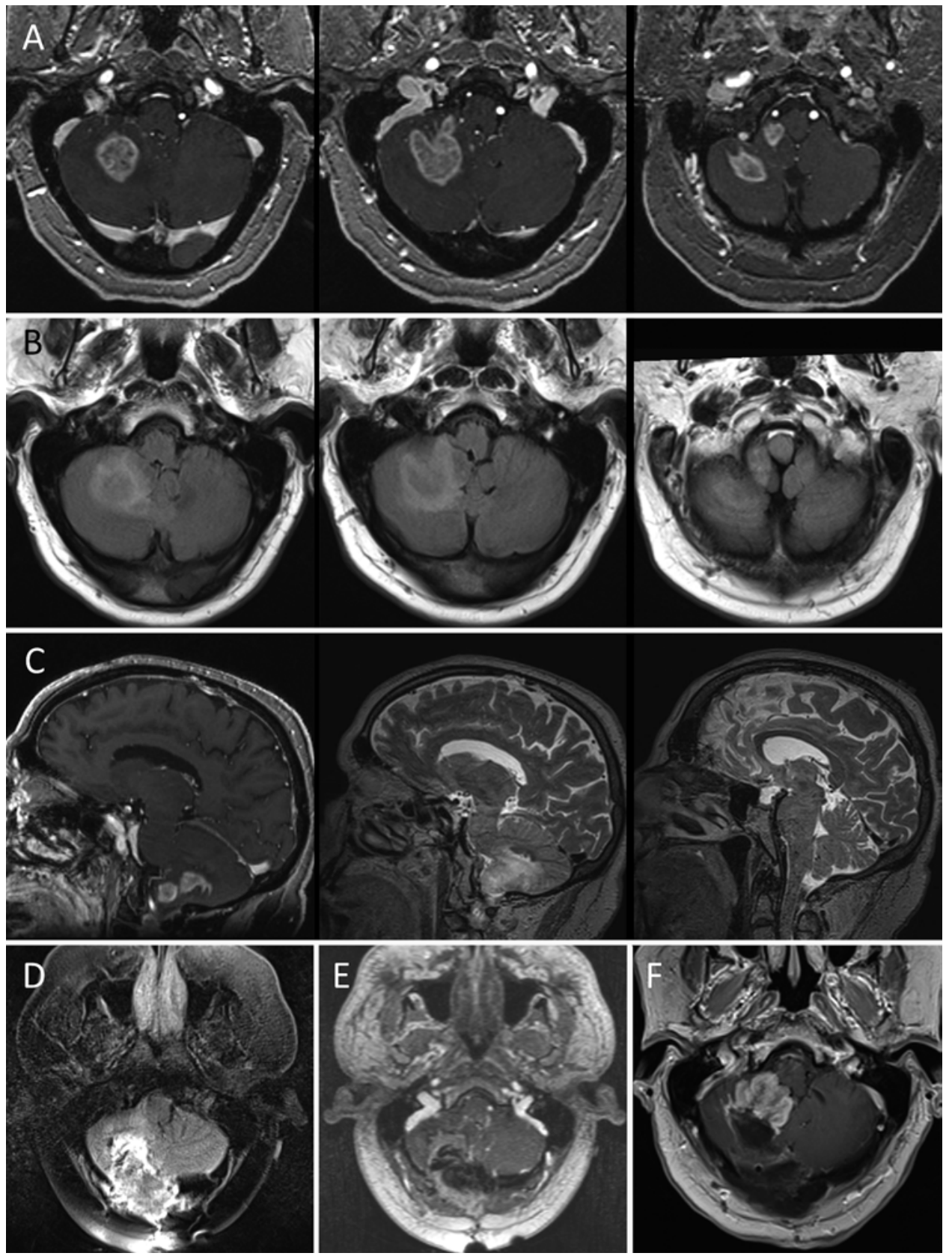

FIG. 3. Postcontrast T1-weighted (A) and T2 FLAIR (B) images demonstrating a new homogeneously enhancing mass with surrounding satellite enhancing lesions in the inferior right cerebellar hemisphere extending into the right cerebellar tonsils. The lesion demonstrates a small amount of surrounding edema, which results in mass effect on the fourth ventricle and adjacent brainstem. C: Sagittal postcontrast T1-weighted (left) and T2-weighted (center) images in the plane of the most medial aspect of the cerebellar lesion, as well as a sagittal T2-weighted midline image (right), demonstrating no direct connection between the previously resected MONG and the newly diagnosed lesion. D and E: Intraoperative MR images obtained immediately after resection of a right cerebellar mass. Postcontrast T1-weighted (D) and T2-weighted FLAIR (E) images demonstrating no abnormal residual contrast enhancement but heterogeneously increased T2 signal intermixed with T2 hypointensity in the right cerebellar surgical bed and in the right middle cerebellar peduncle, indeterminate for residual tumor. F: Follow-up MR image obtained 1 month postoperatively, demonstrating enhancing multilobulated mass lesion along the anterior and medial margin of the surgical cavity representing progressive glioblastoma, causing mass effect on the medulla oblongata and fourth ventricle.

vein occlusion, ${ }^{21}$ or neurosarcoidosis, ${ }^{15}$ which are included in the differential diagnosis at the time of presentation, may initially lead to the misdiagnosis of this rare condition. Moreover, the differential diagnosis of neoplastic lesions of the optic nerve may include low-grade glioma, ${ }^{10}$ meningioma, lymphoma, craniopharyngioma, pituitary adenoma, ${ }^{5}$ and metastasis. ${ }^{1}$ Abou-Zeid et al. presented a case of MONG that was initially thought, based on neuroimaging, to represent a metastasis in a patient with an asymptomatic renal mass. ${ }^{1}$ To further illustrate the 

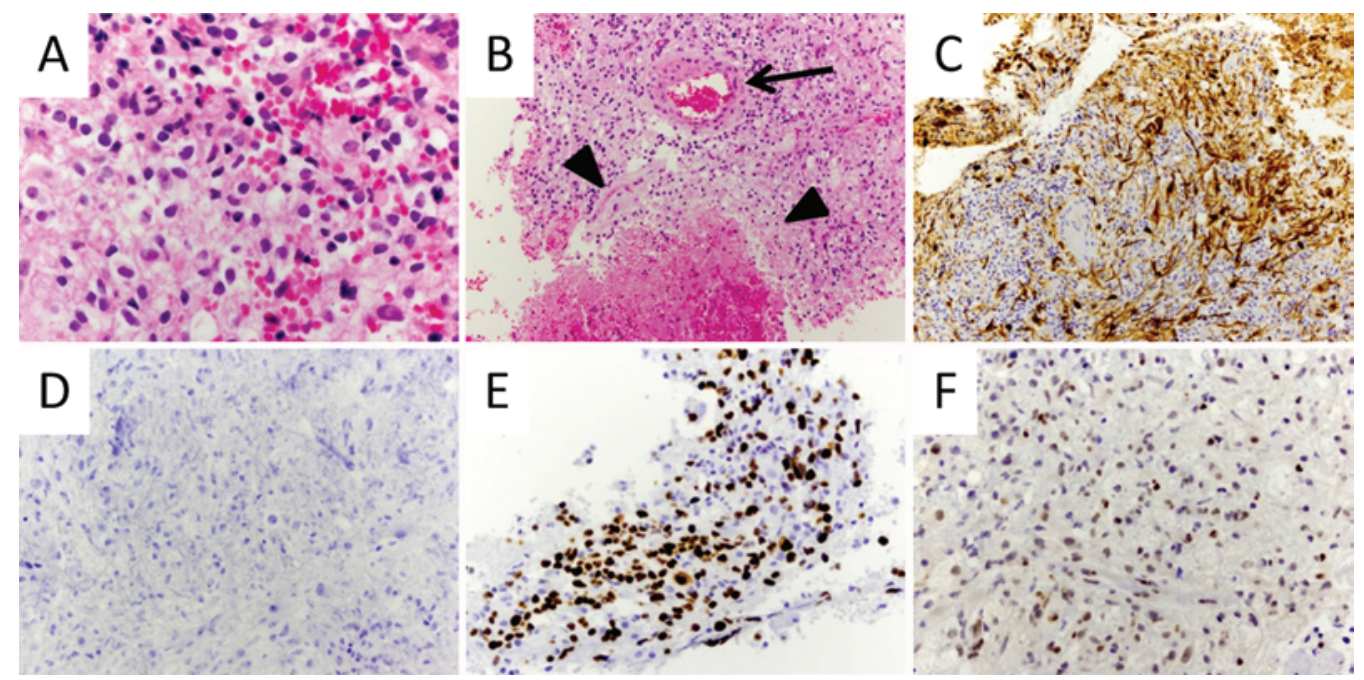

FIG. 4. Histopathological examination of an optic nerve glioblastoma. A: The tumor shows sheets of fibrillary, pleomorphic cells that infiltrate diffusely. B: Microvascular proliferation (arrow) and necrosis (arrowheads) are present. C: GFAP immunostain is diffusely positive, consistent with glial differentiation. D: Immunostain for mutated IDH-1 (R132H) is negative. E: A Ki-67 stain confirms a markedly elevated proliferative index. F: Staining for p53 shows positivity in a small percentage of tumor cells. $\mathrm{H} \& \mathrm{E}$ $(A$ and $B)$. Original magnification $\times 10(A), \times 40(B$ and $C), \times 20(D-F)$. Figure is available in color online only.

challenges in the diagnosis of optic nerve glioblastoma, Balachandran et al. reported a case that was initially diagnosed as nonarteritic anterior ischemic optic neuropathy. ${ }^{4}$ The initial histopathological examination of the optic nerve biopsy demonstrated necrosis and scattered neutrophilic infiltration, without evidence of malignancy. However, subsequent MRI showed optic nerve thickening, and repeat biopsy findings were consistent with glioblastoma.

Local recurrences are common in glioblastomas; ${ }^{38}$ up to $90 \%$ of all recurrences occur within $2-3 \mathrm{~cm}$ from the primary lesion, ${ }^{18}$ while remote recurrences involving the contralateral hemisphere occur in only $4 \%$ of cases. ${ }^{32,33}$ Transtentorial spread of malignant gliomas is exceedingly rare, with only 2 previous reports: one of a left frontal glioblasotma ${ }^{36}$ and another of a right temporal anaplastic astrocytoma (WHO Grade III). ${ }^{16}$ Similar to supratentorial glioblastomas, MONGs also tend to recur locally, with 1 report of supratentorial dissemination of MONG to the ipsilateral thalamus, temporal lobe, and midbrain 7 months after diagnosis. ${ }^{19}$ In this report, we present the first case of transtentorial spread of an optic nerve glioblastoma to the cerebellum. Although gliomas arising within the cerebellum account for $0.4 \%-3.4 \%$ of all gliomas and the majority of them are glioblastomas, ${ }^{8}$ the similar histopathology and molecular profiling of the cerebellar lesion and the primary optic tumor, as well as the time course of devel-
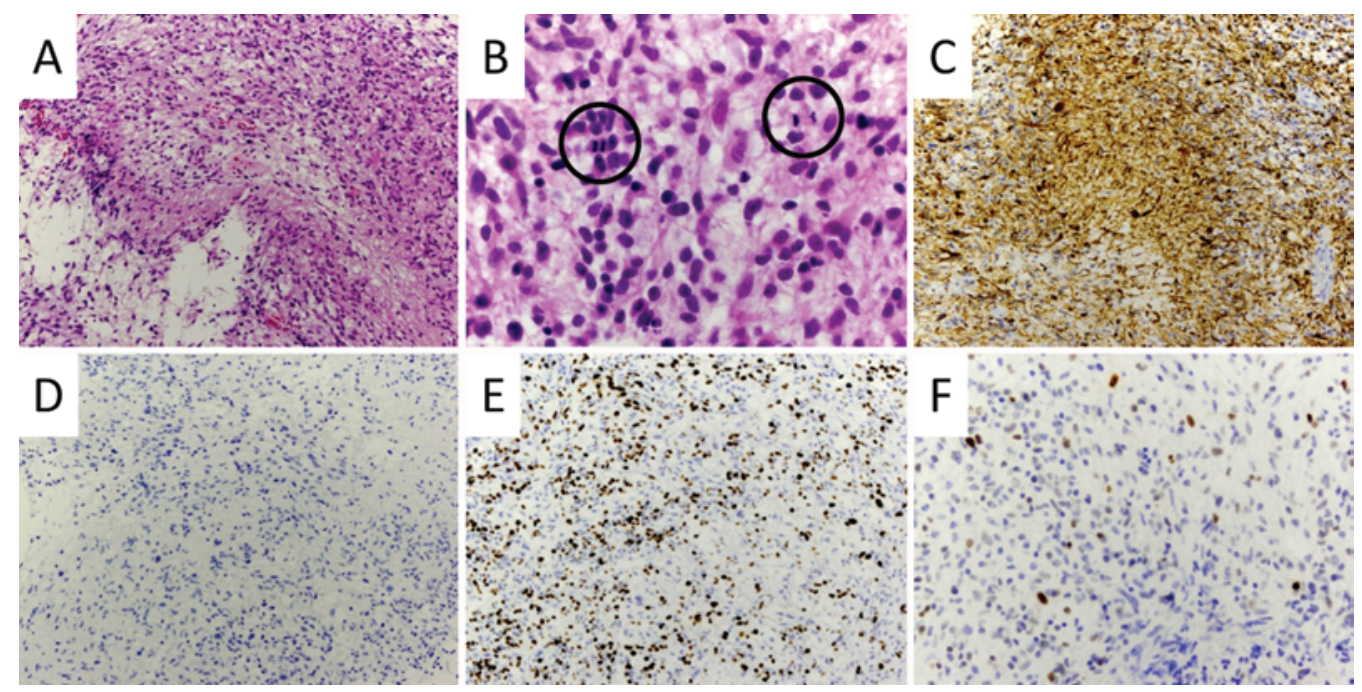

FIG. 5. Histopathological examination of cerebellar glioblastoma. A: The densely cellular glial neoplasm shows areas of necrosis. B: Frequent mitotic figures are present (circled). C: GFAP is diffusely positive. D: Staining for mutant IDH-1 (R132H) is negative. $E$ : Ki-67 shows brisk proliferative activity. $F$ : The majority of tumor cells are negative for $p 53 . H \& E(A$ and $B)$. Original magnification ×10 (A and C-E), ×40 (B), 20 (F). Figure is available in color online only. 


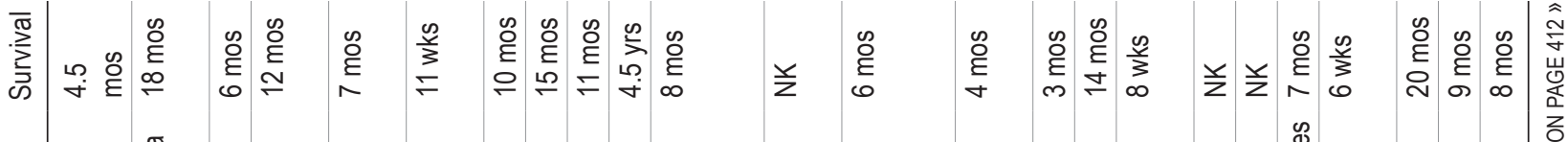

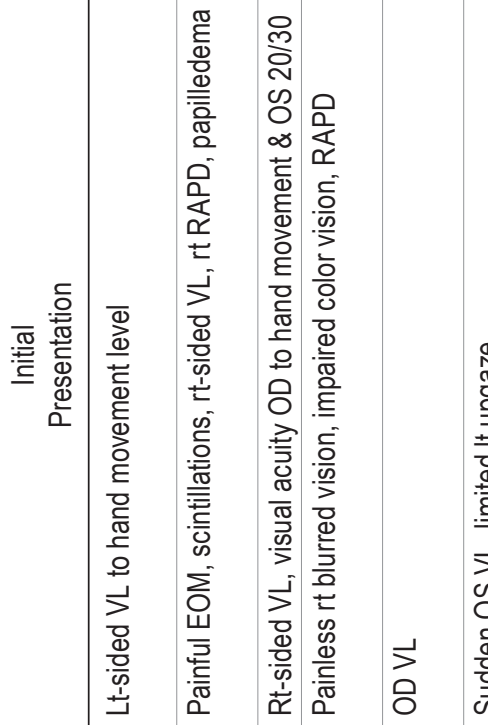

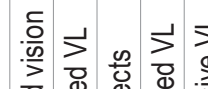

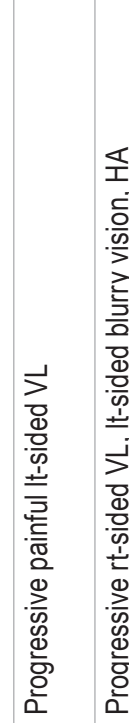

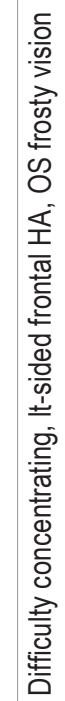

离

空

क

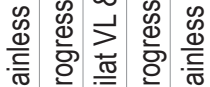

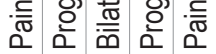

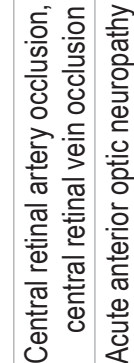

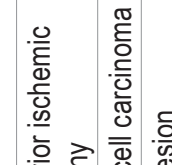

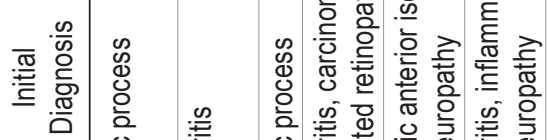

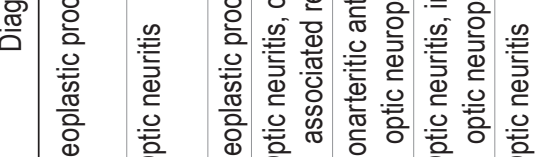

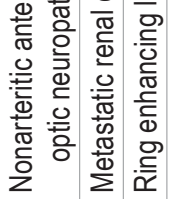

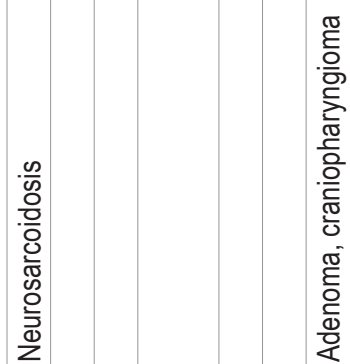
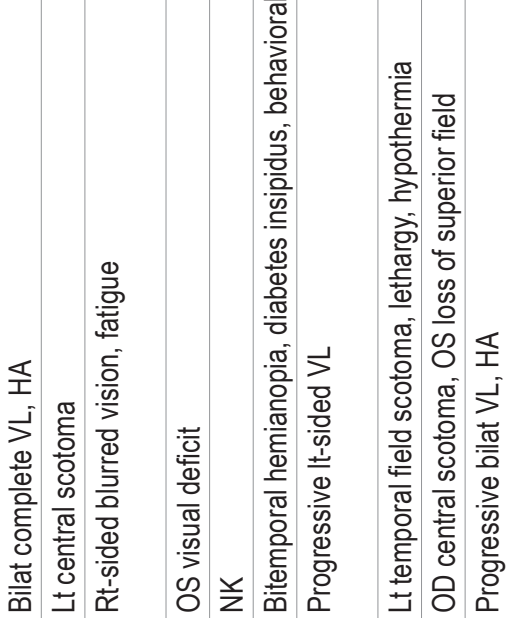

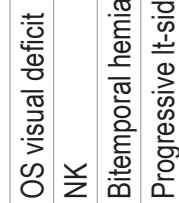

5 ○은

容

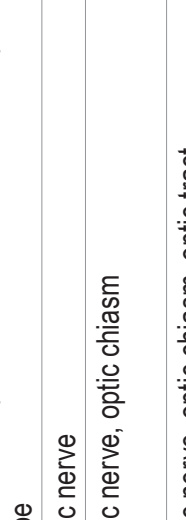

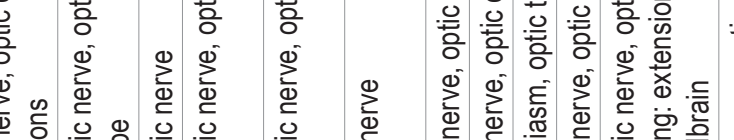

ब्ष

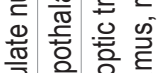

产

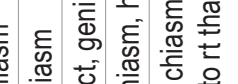

政

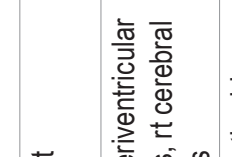

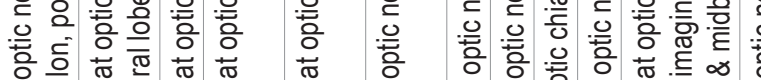

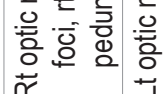

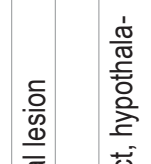

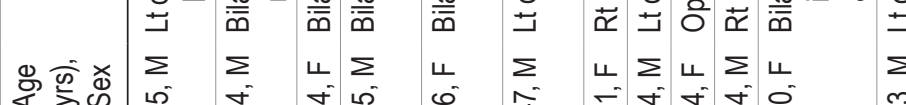

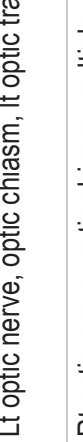

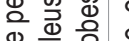

을 을 응

窟

政

둥

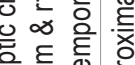

은

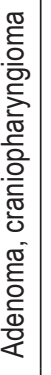

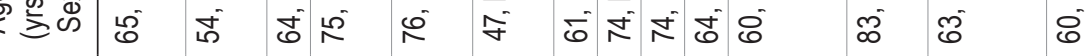

产

t)

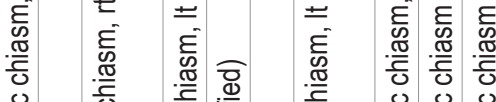

言

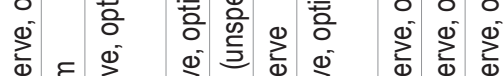

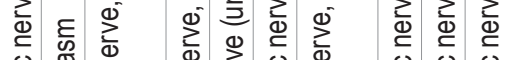
产

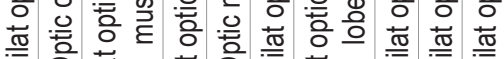
产

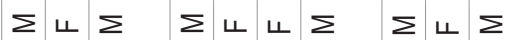

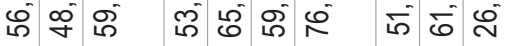

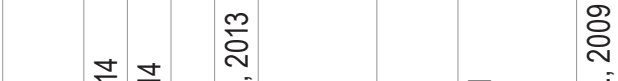

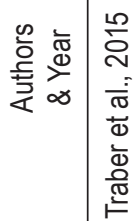

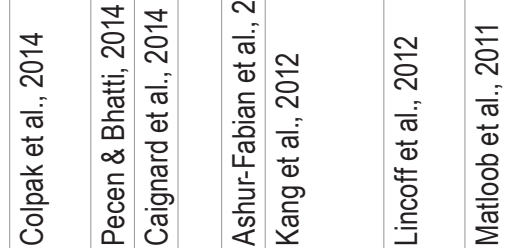

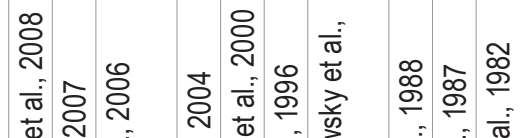

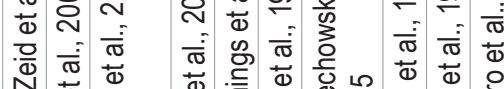

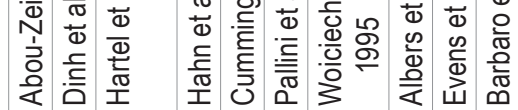




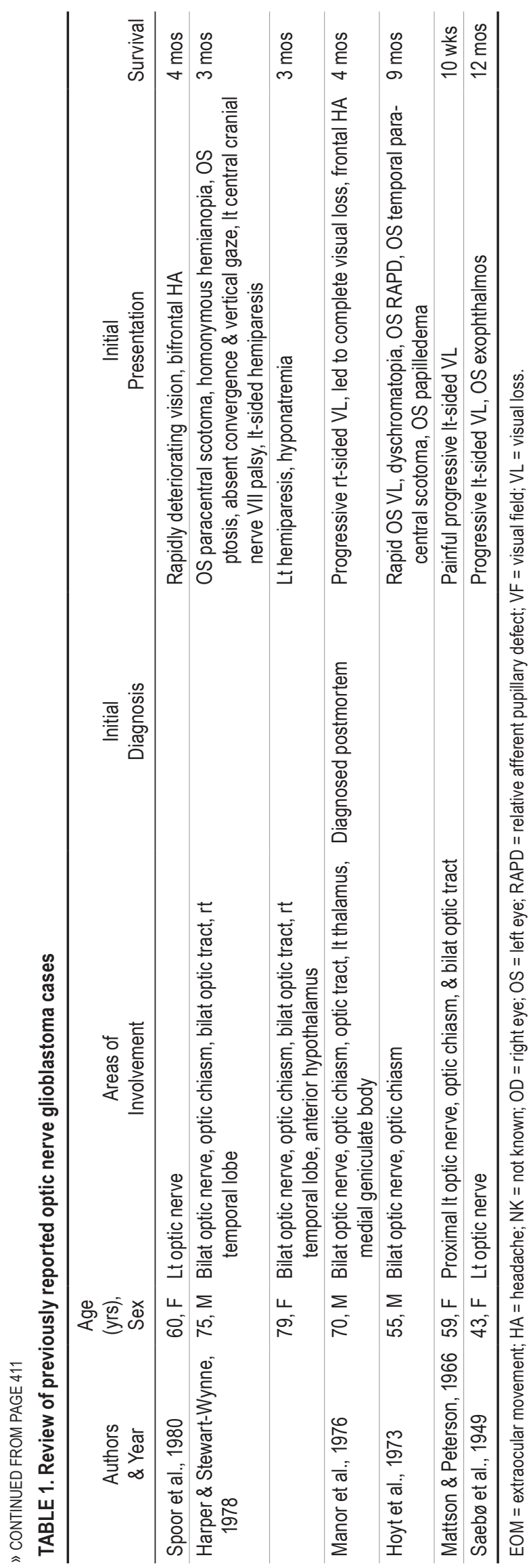

opment suggest transtentorial disease dissemination rather than de novo formation of a cerebellar glioblastoma.

Our patient died 4 months after diagnosis of the recurrent cerebellar lesion, which demonstrated aggressive behavior and rapid progression despite gross-total resection. Patients with glioblastoma recurrence after the initial surgery and chemoradiation therapy are offered a second resection in as many as $58 \%$ of cases, ${ }^{31}$ with a national reoperation average of $14 \%,{ }^{22}$ but the benefit to survival remains controversial. ${ }^{6}$

\section{Conclusions}

We present, to the best of our knowledge, the first case in the literature of transtentorial dissemination of an optic nerve glioblastoma to the cerebellum. Although an optic nerve glioblastoma represents a rare entity and a diagnostic challenge, it should be considered in the differential diagnosis of a patient presenting with rapidly progressive visual loss. Although the overall survival of optic nerve glioblastoma patients may be shorter than that of lobar glioblastoma patients, the management strategies are not substantially different. Specifically, ipsilateral visual preservation should not compromise the extent of resection, and every effort should be made to reduce the risk of disease progression along the unaffected optic pathways to prevent total blindness.

\section{References}

1. Abou-Zeid A, Duplessis D, Gnanalingham KK: Blindness from multiple cerebral gliomas mimicking metastatic brain disease. Br J Neurosurg 22:772-773, 2008

2. Albers GW, Hoyt WF, Forno LS, Shratter LA: Treatment response in malignant optic glioma of adulthood. Neurology 38:1071-1074, 1988

3. Ashur-Fabian O, Blumenthal DT, Bakon M, Nass D, Davis PJ, Hercbergs A: Long-term response in high-grade optic glioma treated with medically induced hypothyroidism and carboplatin: a case report and review of the literature. Anticancer Drugs 24:315-323, 2013

4. Balachandran C, Millar MJ, Murali R, Bulliard C, Malcolm $\mathrm{CM}$, Maloof A: Malignant optic glioma presenting as an acute anterior optic neuropathy. Retin Cases Brief Rep 3:156-160, 2009

5. Barbaro NM, Rosenblum ML, Maitland CG, Hoyt WF, Davis RL: Malignant optic glioma presenting radiologically as a "cystic" suprasellar mass: case report and review of the literature. Neurosurgery 11:787-789, 1982

6. Barker FG II, Chang SM, Gutin PH, Malec MK, McDermott MW, Prados MD, et al: Survival and functional status after resection of recurrent glioblastoma multiforme. Neurosurgery 42:709-723, 1998

7. Caignard A, Faguer R, Mercier P, Menei P, Milea D: Optic nerve and visual pathways primary glioblastoma treated with radiotherapy and temozolomide chemotherapy. Eur J Ophthalmol 24:637-640, 2014

8. Chamberlain MC: Radiographic patterns of relapse in glioblastoma. J Neurooncol 101:319-323, 2011

9. Colpak AI, Isikay I, Mut M, Soylemezoglu F, Kansu T, Foroozan R: Acute visual loss: just the beginning? Surv Ophthalmol 59:548-552, 2014

10. Cummings TJ, Provenzale JM, Hunter SB, Friedman AH, Klintworth GK, Bigner SH, et al: Gliomas of the optic nerve: histological, immunohistochemical (MIB-1 and p53), and MRI analysis. Acta Neuropathol 99:563-570, 2000 
11. Dinh TT, Wang YY, Rosenfeld JV, Cherny M: Glioblastoma of the optic chiasm. J Clin Neurosci 14:502-505, 2007

12. Evens PA, Brihaye M, Buisseret T, Storme G, Solheid C, Brihaye J: [Malignant glioma of the chiasma in adults.] Bull Soc Belge Ophtalmol 224:59-60, 1987 (Fr)

13. Hahn U, Ritz R, Ernemann U: [Glioblastoma multiforme of the optic nerve.] RoFo 176:1700-1701, 2004 (Ger)

14. Harper CG, Stewart-Wynne EG: Malignant optic gliomas in adults. Arch Neurol 35:731-735, 1978

15. Hartel PH, Rosen C, Larzo C, Nestor S: Malignant optic nerve glioma (glioblastoma multiforme): a case report and literature review. W V Med J 102:29-31, 2006

16. Hong CS, Hsieh JK, Edwards NA, Ray-Chaudhury A, Zaghloul KA: IDH mutations may not preclude distant, transtentorial spread in gliomas: a case report and review of the literature. World J Surg Oncol 14:53, 2016

17. Hoyt WF, Meshel LG, Lessell S, Schatz NJ, Suckling RD: Malignant optic glioma of adulthood. Brain 96:121-132, 1973

18. Jansen EP, Dewit LG, van Herk M, Bartelink H: Target volumes in radiotherapy for high-grade malignant glioma of the brain. Radiother Oncol 56:151-156, 2000

19. Kang JJ, Hou JH, Bui KM, Michals E, Valyi-Nagy T, Koshy $\mathrm{M}$, et al: De novo malignant optic chiasm glioma with initial clinical response to steroids. Neuroophthalmology 36:5963,2012

20. Liang BC, Thornton AF Jr, Sandler HM, Greenberg HS: Malignant astrocytomas: focal tumor recurrence after focal external beam radiation therapy. J Neurosurg 75:559-563, 1991

21. Lincoff NS, Chung C, Balos L, Corbo JC, Sharma A: Combing the globe for terrorism. J Neuroophthalmol 32:82-85, 2012

22. Mahaley MS Jr, Mettlin C, Natarajan N, Laws ER Jr, Peace BB: National survey of patterns of care for brain-tumor patients. J Neurosurg 71:826-836, 1989

23. Manor RS, Israeli J, Sandbank U: Malignant optic glioma in a 70-year-old patient. Arch Ophthalmol 94:1142-1144, 1976

24. Matloob S, Fan JC, Danesh-Meyer HV: Multifocal malignant optic glioma of adulthood presenting as acute anterior optic neuropathy. J Clin Neurosci 18:974-977, 2011

25. Mattson RH, Peterson EW: Glioblastoma multiforme of the optic nerve. JAMA 196:799-800, 1966

26. Millar WS, Tartaglino LM, Sergott RC, Friedman DP, Flanders AE: MR of malignant optic glioma of adulthood. AJNR Am J Neuroradiol 16:1673-1676, 1995

27. Pallini R, Lauretti L, La Marca F: Glioblastoma of the optic chiasm. J Neurosurg 84:898-899, 1996

28. Pecen PE, Bhatti MT: Clinical reasoning: a 61-year-old woman with a swollen optic nerve and progressive visual loss. Neurology 82:e205-e209, 2014

29. Rousseau A, Mokhtari K, Duyckaerts C: The 2007 WHO classification of tumors of the central nervous system-what has changed? Curr Opin Neurol 21:720-727, 2008

30. Saeb $\varnothing$ J: Primary tumour of the optic nerve, glioblastoma multiforme. Br J Ophthalmol 33:701-708, illust, 1949

31. Salcman M, Scholtz H, Kaplan RS, Kulik S: Long-term sur- vival in patients with malignant astrocytoma. Neurosurgery 34:213-220, 1994

32. Seiz M, Nölte I, Pechlivanis I, Freyschlag CF, Schmieder K, Vajkoczy P, et al: Far-distant metastases along the CSF pathway of glioblastoma multiforme during continuous low-dose chemotherapy with temozolomide and celecoxib. Neurosurg Rev 33:375-381, 2010

33. Sherriff J, Tamangani J, Senthil L, Cruickshank G, Spooner $\mathrm{D}$, Jones B, et al: Patterns of relapse in glioblastoma multiforme following concomitant chemoradiotherapy with temozolomide. Br J Radiol 86:20120414, 2013

34. Spoor TC, Kennerdell JS, Martinez AJ, Zorub D: Malignant gliomas of the optic nerve pathways. Am J Ophthalmol 89:284-292, 1980

35. Traber GL, Pangalu A, Neumann M, Costa J, Weller M, Huna-Baron R, et al: Malignant optic glioma-the spectrum of disease in a case series. Graefes Arch Clin Exp Ophthalmol 253:1187-1194, 2015

36. van Nifterik KA, Elkhuizen PH, van Andel RJ, Stalpers LJ, Leenstra S, Lafleur MV, et al: Genetic profiling of a distant second glioblastoma multiforme after radiotherapy: recurrence or second primary tumor? J Neurosurg 105:739-744, 2006

37. Wabbels B, Demmler A, Seitz J, Woenckhaus M, Bloss HG, Lorenz B: Unilateral adult malignant optic nerve glioma. Graefes Arch Clin Exp Ophthalmol 242:741-748, 2004

38. Wallner KE, Galicich JH, Krol G, Arbit E, Malkin MG: Patterns of failure following treatment for glioblastoma multiforme and anaplastic astrocytoma. Int J Radiat Oncol Biol Phys 16:1405-1409, 1989

39. Woiciechowsky C, Vogel S, Meyer R, Lehmann R: Magnetic resonance imaging of a glioblastoma of the optic chiasm. Case report. J Neurosurg 83:923-925, 1995

\section{Disclosures}

The authors report no conflict of interest concerning the materials or methods used in this study or the findings specified in this paper.

\section{Author Contributions}

Conception and design: Mastorakos, Chen, Ding, Lopes, Shaffrey. Acquisition of data: Mastorakos, Hays, Caruso, Ding, Taylor, Shaffrey. Analysis and interpretation of data: Hays, Caruso, Chen, Taylor, Lopes. Drafting the article: Mastorakos, Hays, Caruso, Chen, Lopes. Critically revising the article: Mastorakos, Hays, Chen, Ding, Taylor, Lopes, Shaffrey. Reviewed submitted version of manuscript: Mastorakos, Hays, Chen, Ding, Taylor, Lopes, Shaffrey. Approved the final version of the manuscript on behalf of all authors: Mastorakos. Study supervision: Lopes, Shaffrey.

\section{Correspondence}

Panagiotis Mastorakos, Department of Neurological Surgery, University of Virginia Health System, Box 800212, Charlottesville, VA 22908. email: pm5mt@virginia.edu. 